\title{
Zweite Notiz zur Kenntnis des Novains. Von
}

\author{
Fr. Kutscher.
}

(Aus dem physiologischen Institut der Universität Marburg.)

(Der Redaktion zugegangen am 3. Dezember 1906.)

Im vorletzten Hefte dieser Zeitschrift habe ich eine Methode angegeben, um aus den Rückständen des mit Barỵt destillierten Novains charakteristische Spaltungsprodukte $z u$ isolieren. Man säuert dazu die Rückstände stark mit Schwefelsäure an und erschöpft sie mit Äther. Der Äther nimmt dann mehrere Säuren auf, unter anderen auch Bernsteinsäure. Die Bernsteinsäure ließ sich infolge ihrer ausgezeichneten Krystallisationsfähigkeit von den anderen Säuren abtrennen und durch ihre Reaktionen und Analyse als solche charakterisieren. Zur Analyse wurde sie in ihr Silbersalz übergeführt. Ich gebe im folgenden die erhaltenen Analysenzahlen.

$0,1386 \mathrm{~g}$ Substanz gaben $0,0150 \mathrm{~g} \mathrm{H}_{2} \mathrm{O}, 0,0756 \mathrm{~g} \mathrm{CO}_{2}$ und $0,0897 \mathrm{~g} \mathrm{Ag}$. 0,1130 * \ $, 0,0732>\mathrm{Ag}$.

$$
\begin{array}{ccc} 
& \text { Für } \mathrm{C}_{4} \mathrm{H}_{4} \mathrm{Ag}_{8} \mathrm{O}_{4} & \\
\text { Berechnet: } & & \text { Gefunden: } \\
\mathrm{H}=1,2 \% & \mathrm{H}=1,2 \% \\
\mathrm{C}=14,5 \% & \mathrm{C}=14,9 \% \\
\mathrm{Ag}=65,0 \% & \mathrm{Ag}=64,7 ; 64,8 \%
\end{array}
$$

Die freie Bernsteinsăure schmolz bei $182^{\circ} \mathrm{C}$. 